and in a genuine sense of community of enlightened interests among the workers themselves. While the dangers that the vulnerability of unorganized workers may be abused are real, the activities of ephemeral and sometimes bogus labour organizations which do not command the loyalty of workers or serve their genuine interests may be ultimately as harmful to their welfare and working conditions. A significant instance of often serious indifference among the people themselves to improvements in working conditions and hours, when immediate money returns are held to be paramount, was found among Chinese brick workers in Malaya, who refused to agree to the curtailment of an 84-hour week.

The difficulties in applying Western standards of social security in Colonial territories like Ceylon and Malaya, where even under conditions of comparative prosperity national income and Government financial resources are so limited, becomes very plain. It would have been interesting in this context to have learnt how far work on plantations and in the towns has undermined the solidarity of family group life. These groups frequently provide their own mutual insurance and spreading of risks under peasant conditions. But they have proved very vulnerable in many territories to the introduction of personal incomes from wage labour. Their protection against rapid disintegration while alternative forms of group organization or social services are developed in their place poses a serious problem in applied sociology.

The vicious circle of poverty, under-nourishment, poor health and low output of labour, which does not in consequence earn an adequate purchasing power, is more than generally obvious in Mauritius. The attempt to break this circle should, as Major Orde Browne emphasizes, underlie all development plans and in particular it should include full attention to the need for improving the feeding and thereby the health of the rising generation through the provision of school meals and other means of raising nutritional standards.

As has been indicated, these reports emphasize the need for a comprehensive view of the context of Colonial labour problems. Of the many lessons to be learned there is perhaps special need for emphasis on one which does not find direct expression in the reports themselves. Major Orde Browne alludes at every turn to the lack of adequate data for the analysis of the actual situations and confident formulation of policy. $\mathrm{He}$ makes some recommendations for additional appointments and duties in the Labour Departments; but the complexity of the problems and the many gaps in existing information all point to the need for the earliest possible programme for social surveys in the Colonial Empire by trained investigators. Reports such as these leave little doubt as to the general nature of the problems, but for the proper selection and integration of development projects a more adequate and comprehensive body of empirical data is needed. We have so far in the British Empire paid too little attention to the development of applied sociology, to the training of field workers and the organization of comprehensive investigations. Much could be learned from substantial American experience and achievements in this field. The latter have been remarkable for their investigations and the planning of remedial projects in backward or depressed areas. Colonial development offers one among several opportunities for the fruitful application of the social sciences, and valuable work of this kind is beginning in the West Indies. The provision and harnessing o a sufficient body of workers, trained in social anthro pology, survey methods and rural economics needec for this task are long overdue. Such training anc organization will take time, and the earliest star should be made in preparing for them immediately after the War.

DARYLL FORDE.

\section{MODERN DRUGS AND TROPICAL DISEASES}

WHEN primitive man first began to use tools, he presumably employed stones or branches which he found fortuitously in shapes suitable for his pur. pose. Later he learnt how to fashion implements by simple modifications of pre-existing material, and in recent years he has built the vast and complicated machines which now sustain our moderm civilization. A similar, but less extensive, progress can be seen in the realm of therapeutics. For long ages medical men were restricted to simple herbal and mineral remedies; then steps were taken to isolate the active alkaloids and other principles and to make simple chemical modifications in them; lastly, since the days of Ehrlich and his predecessors, therapy has come to rely more and more on compounds synthesized especially for this purpose by the organic chemist, on lines previously unknown in the vegetable, animal, or mineral worlds. This modern state of drug therapy is well illustrated by a discussion which was held at the Royal Society of Tropical Medicine and Hygiene on July 14 on "Modern Drugs in the Prevention and Treatment of Tropical Diseases". The only drug of natural origin which was mentioned was quinine, the purified alkaloid from cinchona bark. All the other substances discussed were compounds which have been prepared for the first time not more than ten or twenty years ago.

The chief speaker was Colonel S. P. James. $H_{\theta}$ began by referring to the great contributions made to our knowledge of the subject by the late Prof. Warrington Yorke, whose recent untimely death was also deplored by other speakers. Yorke was the first to examine scientifically by controlled experiments the practice of trying to sterilize a malarial infection by giving quinine in very large doses for a long period. He made three outstanding observations. The first was that quinine, however and whenever it is given, does not prevent infection from the bite of mosquitoes carrying malaria. The second was that, at the onset of the primary attack, quinine has no action at all until a good many parasites are present in the peripheral blood. The third was that quinine, however and whenever it is given, does not prevent malaria from relapsing. The therapeutic value of quinine and of the other main antimalarial compound mepacrine ('Atebrin') lies in their power to prevent the infection from developing into the clinically recognizable disease (suppressive treatment or prophylaxis) and to cut short the actual attacks of the disease (curative treatment). Although it is not possible to kill off all the malaria parasites in the body, and although, when treatment has ceased, they will sooner or later reappear causing a relapse, com. plete cure will eventually be produced by the develop. ment of immunity in the patient after a number of attacks have occurred. To control the clinical manifestations of the disease in this way, quite small 
doses are sufficient, for example, 10 grains of quinine or $0.1 \mathrm{gm}$. mepacrine given three times a day. Doses larger than these produce no greater therapeutic result (apart from the 'loading' dose mentioned below) but only exert a toxic influence on the patient, who exchanges the poison of the parasite for that of the physician.

The explanation of these limitations on the action of antimalarial drugs must lie in a more complete knowledge of the biology of the malaria parasite. As is well known, there is an asexual cycle in the blood of man in which the parasite (trophozoite) gradually enlarges and then divides (schizogony) into 16 or 32 small forms, each of which enters a new blood corpuscle and becomes a new trophozoite; in benign tertian and malignant subtertian malaria this cycle occupies forty-eight hours. There is also the invertebrate cycle, starting from the sexual cells (gametocytes) swallowed by the mosquito, which conjugate and form cysts in the insect's stomach; these cysts liberate countless smaller forms (sporozoites) which pass into the salivary glands and are inserted into man again when the mosquito bites; this cycle occupies about ten days. These two cycles have been known for forty years, but there is considerable obscurity as to the stages which occur between the injection of the sporozoites into the new host and the appearance of parasites (trophozoites) in the blood; in human infections this latent period occupies about two weeks. The work of James, Raffaele and others has shown that in certain types of bird malaria (due to Plasmodium gallinaceum and $P$. relictum) the sporozoites first develop in endothelial cells and macrophages, and not in the red blood corpuscles (erythrocytes) which form the host cells for the well-known asexual cycle of trophozoites and schizonts mentioned above. These new forms are known as the 'exoerythrocytic' parasites. Presumably they ultimately give rise to the ordinary trophozoites. They are almost completely resistant to the action of the antimalarial drugs known at present; in young birds they often reappear after the main wave of the blood infection has been overcome, and they cause death from massive growth in the capillaries of the brain and other organs. The occurrence of such exoerythrocytic forms in human malaria would explain many of the limitations of drug therapy described above, but unfortunately such forms have not yet been demonstrated. Col. James expressed his belief that they would eventually be found in man, but other speakers were more sceptical.

be that as it may, the importance of intensive research on the biology, chemotherapy, and other aspects of the malaria parasite ought to be clear to all. In the War of 1914-18, malaria was an important military factor, and apparently it looms large in this War also. According to a recent broadcast by a member of the Australian Government, 80 per cent of the Australian troops who were landed in New Guinea went down with malaria. Although the details about other localities are rightly withheld by the authorities, it requires little imagination to visualize the great handicap to military operations and the great losses in men's efficiency and lives which this disease must be causing. Money devoted to the search for weapons to combat such a deadly menace is money well spent. Unfortunately, this truism has not been properly appreciated in Great Britain during the last thirty years, and support for such research has been limited, etiolated, and spasmodic. The sums spent on the conquest of malaria have been insignificant compared with those employed in trying to persuade people to change their brand of cigarette, or to alter their opinion about the nutritive value of beer. This is the more sur. prising since so many British Colonies lie in the tropics; and non-British have been apt cynically to express surprise that the wealthy British Empire, which probably suffers greater harm from malaria than any other community in the world, has been content to depend on the Dutch of Java for its quinine and on the German chemists for its synthetic antimalarial compounds. Colonel James concluded by hoping that this sorry state of affairs would be remedied in the future.

The next speaker, Dr. F. Hawking, described the valuable contributions made by Prof. Warrington Yorke to the chemotherapy of trypanosomiasis (sleeping sickness). By devising a simple technique for maintaining trypanosomes alive in vitro, he made it possible to study the action of drugs on the parasite without the complications and obscurities due to the intervention of the animal host. By this means Yorke showed that arsenicals exert a direct action upon the trypanosomes. Further work showed that normal trypanosomes actively absorb the drug, which becomes concentrated in the parasite and eventually poisons it. On the other hand, trypanosomes which have become arsenic-resistant or 'arsenic fast' fail to absorb the drug and so they survive. This explanation of the resistance of arsenic-fast trypanosomes, which had been postulated by Ehrlich on theoretical grounds, thus received its experimental verification. Yorke's last big contribution to chemotherapy was the discovery (in collaboration with Dr. H. King, Dr. A. J. Ewins and others) of the diamidine compounds such as prop. amidine :

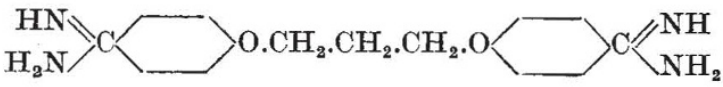

These compounds are very active in the treatment of human trypanosomiasis, but the dose is limited by their toxicity; moreover, they do not penetrate the central nervous system, so that infections which have reached the brain cannot be sterilized. Accordingly it is probable that they will not replace the compounds at present in use, namely, tryparsamide and suramin (Bayer 205). On the other hand, they have proved very valuable in the treatment of kala azar, especially in the case of the resistant type which occurs in the Sudan, and this will probably prove their most important field of use. They are also effective in the treatment of babesiasis of dogs and other animals. Recently through the work of Fuller, and of Thrower and Valentine, propamidine has been found to exert a powerful action against bacteria and it has been employed with much success as a dressing for burns and other superficial wounds.

The greatest triumph of modern chemotherapy has been the discovery of the sulphonamide compounds, following the description of prontosil, by Domagk in 1935. Many of the bacterial infections of temperate climates which respond to these compounds occur in the tropics also ; and sulphonamides have been invaluable in the Colonies in the treatment of pneumonia, cerebrospinal meningitis, gonorrhœa and other conditions. Among the infections more specific- 
ally tropical which are cured by these drugs, the chief one is bacillary dysentery. Dysentery is one of the four or five major infections of the tropics, and the introduction of sulphaguanidine by Marshall in 1940 has revolutionized its whole treatment. Previously the physician could apply only palliative measures, and the recovery of the patient depended mainly on the power of his constitution to overcome the invading micro-organisms. Now, the infection can be cut short in its early stages by a direct attack upon the offending bacilli. Dysentery has affected many of our troops in the Middle East, although the incidence has been kept much lower than it was in the War of 1914-18 by strict measures concerning the disposal of fæces and fly control. The use of sulphaguanidine has cut short the period spent in hospital, avoided much chronic invalidism and saved many lives. Yet another major disease has been brought under the control of the sanitary inspector'to prevent it, and of the physician to cure it.

Another disease, more dreaded but less common, which responds to sulphonamide therapy is plague. In 1941 there was an epidemic in Nairobi, involving more than 240 patients, and Plum found that sulphapyridine given in large doses to early cases produced a dramatic improvement in their condition; if the treatment was not given until later, the infection was often too far advanced for the patient to be saved. Unfortunately other important infections of the tropics such as undulant fever (due to Brucella melitensis), typhus and typhoid are not affected by sulphathiazole and similar compounds.

Sulphonamides have a moderate action against human malaria, an action which is greater on malig nant subtertian than on benign tertian. But since this action is less intense than that of the drugs at present in use (quinine and atebrin), its existence is of little practical importance at the present time, although it forms the starting-point for chemotherapeutic research which may eventually yield more active remedies.

The older forms of chemotherapy, such as those for malaria and for sleeping sickness, have something to learn from the newer principles which have been evolved from experience with sulphonamides. For one thing, the rational use of synthetic drugs is greatly facilitated if their blood concentration can be estimated and the dosages regulated accordingly. In the case of suramin (Bayer 205, antrypol) used for sleeping sickness, this is already possible through the work of Prof. A. C. Wormall ; and the treatment of Europeans affected with the disease ought to be controlled in this manner, in order to avoid the disastrous relapses which may occur in patients who fail to retain the compound in adequate amounts. In the case of mepacrine (atebrin) used for malaria, methods will shortly become available, and then revision of the doses accepted at present may be necessary. A second principle derived from experience with sulphonamides is the rule of starting treatment with a large initial 'loading dose'. In this way, the unnecessary delay in raising the blood concentration to its effective level by a gradual accumulation of equal small doses can be avoided. Such a practice might well be adopted when mepacrine is administered for an acute attack of malaria. Instead of giving the customary course of $0.1 \mathrm{gm}$. three times a day for five days, in which case an effective concentration in the blood is probably not reached until the second day, it was suggested that the first dose might well be $0.6 \mathrm{gm}$. (or even $0.9 \mathrm{gm}$.) and that subsequent doses should be correspondingly reduced. It was also pointed out that although intramuscular injections of mepacrine are sometimes necessary, and although they are effective in getting the drug into the blood rapidly, they always cause a certain amount of necrosis at the site of injection, and should be avoided whenever possible.

Other speakers in the discussion described their own experiences with drugs and tropical diseases. Dr. H. M. Hanschell said that propamidine exerted a powerful curative action on infections of Trichomonas vaginale or of Ducrey's bacillus, but it was not more effective than the remedies already in use, and it often caused toxic symptoms; consequently it was not likely to be adopted for routine use in these diseases. $\mathrm{He}$ defended the synthetic chemists against some of the slurs cast upon them, saying that if they were expected to produce new drugs against infections, they ought to be given more information about the biology of the micro-organisms; this information could be gained only by more extensive research upon the malaria parasite and other offending Protozoa and bacteria.

Prof. K. B. Williamson mentioned some personal experiences with malaria in Malaya.

Major J. W. Howie, who had recently returned from Nigeria, described observations on soldiers taking quinine. Some persons failed to absorb the quinine completely in the intestine, or they got rid of it from the body with abnormal rapidity, and these persons were not properly protected by prophylactic quinine against the onset of attacks of malaria, nor were they readily cured by it when quinine was given for their fever.

Dr. W. D. Nicol brought forward observations made by himself and Mr. P. G. Shute at the Ministry of Health's Malaria Laboratory at Horton. Suitable doses of mepacrine given to four volunteers had prevented all infections from the bites of mosquitoes infected with subtertian malaria. In these cases, mepacrine had acted as a true prophylactic, destroying the sporozoites which the insect injected.

Dr. A. R. D. Adams spoke as one who had long been associated with Prof. Warrington Yorke, to whom he paid high tribute. The diamidine compounds had been used for the successful treatment of several cases of Indian kala azar at the Liverpool School of Tropical Medicine and no toxic complica. tions had been encountered.

Major-General A. G. Biggam was able to give more cheering information about the other diseases of our forces in the tropics. The use of sulphaguanidine for the treatment of bacillary dysentery has been most satisfactory, and in most patients the progress of this disease is rapidly cut short. Succinyl-sulphathiazole (sulphasuxidine) is equally effective and satisfactory, although presumably the supply is more limited. Sulphapyridine and sulphathiazole are effective therapeutically, but they are more likely to cause toxic effects (vomiting and blockage of the urinary passages). Sulphanilamide is not effective. Succinyl-sulphathiazole has also been tried against typhoid fever; against the infection itself it is powerless, but it may help to prevent distension, although this is not certain. Kala azar in the Sudan responds well to stilbamidine (introduced by the late Prof. Warrington Yorke), but unless the solution is freshly prepared toxic reactions may occur. Tropical ulcers which often occur on the legs, and which are a most important cause of disability among native workers, have been much improved by the local application 
of penicillin, although presumably the supply is too limited for this treatment to be used extensively. Relapsing fever due to Trep. recurrens has caused trouble in Abyssinia and the Middle East; in some places, the response to neo-arsphenamine has been disappointing, and stovarsol, tryparsamide or bismuth have been more satisfactory. When "the medical history of the present War can be described in full, because peace has come, it will include many interesting features.

F. Hawking.

\section{ANTOINE LAURENT LAVOISIER, 1743-1794}

\section{By Prof. J. R. PARTINGTON, M.B.E. Queen Mary College, University of London}

$\mathrm{A}$ NTOINE Laurent Lavoisier, the architect of modern chemistry, was born in Paris on August 26, 1743. His father was an advocate and his mother the daughter of an advocate. The fortunes of the family of Lavoisier had progressed from employees in the postal service, through trade, to the legal profession, and although the father was not wealthy, the maternal grandmother had ample means and arranged for the boy's education. He attended as a day scholar at the famous Mazarin College in Paris, then notable in providing excellent teaching in science. Here he remained to the age of seventeen, when he began to prepare to enter the profession of law. His teachers, Guettard in geology, Bernard de Jussieu in botany, and especially Rouelle in chemistry, had, however, implanted in him a love of science. At first he was most attracted to mathematics and meteorology. $\mathrm{He}$ acted for three years as assistant to Guettard in a survey for a geological map of France. In the intervals of the necessary journeys he wrote an essay for the Royal Academy of Sciences, which had offered a prize for a description of the best method of lighting the streets of a large town. Lavoisier's essay did not gain him the prize, but he received a gold medal and the honour of having his essay published.

This early association with applied science was to continue throughout his life, and he later carried out a very large amount of work in the service of the French Government. The latter, during the early part of the seventeenth century, and in association with the Royal Academy of Sciences, had taken a keen interest in the application of science to arts and industries, and the spirit of the organization of knowledge which found its expression in the "Encyclopædia" was also manifested in the publication of several large and richly illustrated volumes dealing with various trades. The idea that it is a matter of political importance to have existing knowledge summarized and rationalized for the public benefit is, therefore, not a new one, and it found extensive and fruitful application in pre-revolutionary France. The six large volumes of the collected works of Lavoisier, published in the period 1864-93, are largely devoted to his many investigations on applied science, such as the manufacture of gunpowder, and he gave a large amount of time and energy to such public services.

The Royal Academy of Sciences, founded by Louis XIV in 1666, elected Lavoisier to membership in 1768, at the early age of twenty-three. In 1764 he had published a paper on gypsum, but at this time he had done no scientific work of real importance. In 1768 he also entered the Ferme Générale, an association which, in return for a sum paid to the Government, fixed periodically, had the right to collect from the taxpayers whatever sum they could be induced to part with. As might be expected, the members of the Ferme varied considerably in their methods, and there was some harsh administration, so that the association as a whole laid up for itself a growing store of hatred and contempt which was later to play a large part in the Revolution. Whatever pretext was offered for the execution of Lavoisier, it was actually his association with the F'erme which sealed his fate. He carried out his duties honestly and, we may be sure, humanely, but he also made large profits. These enabled him to carry on very expensive researches, and his work is noteworthy in the use of elaborate-often over-elaborate-apparatus, and much of it was outside the means of other scientific men.

In 1771 Lavoisier married Marie Anne Pierrette Paulze, the daughter of a member of the Ferme, then in her fourteenth year. Madame Lavoisier, although so young, set herself the task of becoming an assistant and amanuensis in his scientific work, and besides being a capable and affectionate wife she also, with her notable linguistic and artistic ability, gave him very effective help in his researches and publications. The charming illustrations in his famous "Traité élémentaire de Chimie" (1789) are from drawings which she made.

The scientific work of Lavoisier has a marked character. He discovered no new substances, devised no really novel apparatus, and worked out no improved methods of preparation. He was essentially a theorist, but a theorist of a most original, drastic and revolutionary kind. It must not be supposed that scientific chemistry originated with him, although he undoubt. edly gave it a new form, which it still carries. From the beginning of the seventeenth century, with the work of such men as Van Helmont, Boyle, Glauber, Lemery and Stahl, a very important body of systematized knowledge had grown up which constituted a true science of chemistry. The underlying theory, when Lavoisier began his work, was the doctrine of phlogiston. This was primarily intended to explain the phenomena of combustion and the calcination of metals. The theory assumed that combustibles and metals contained a common, identical, and transferable entity called phlogiston, which they lost when burnt or calcined; the theory was also widely extended to other chemical phenomena. There had also been good quantitative work, notably that of Black (whose researches served as a model for Lavoisier's) and Bergman. The focusing of attention on combustion phenomena by Lavoisier, and theoverwhelming importance which he conferred on oxygen, must not be allowed to obscure the fact that a large part of chemistry lies outside this region, and that much fundamental and important research had already been carried out in this wider field.

Lavoisier's great merit lay in his capacity of taking over experimental work carried out by others (whose claims he, unfortunately, did not always sufficiently recognize or admit in his published memoirs or his books), and by a rigorous logical procedure, based on the results of quantitative experiments which he himself made, of expounding the true explanation of the results. This explanation, that combustion and calcination consist in the union 